\title{
Machine-learning phenotypic classification of bicuspid aortopathy
}

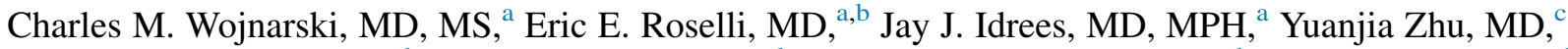 \\ Theresa A. Carnes, MPH, ${ }^{\mathrm{d}}$ Ashley M. Lowry, MS, ${ }^{\mathrm{d}}$ Patrick H. Collier, MD, PhD, ${ }^{\mathrm{b}, \mathrm{e}}$ Brian Griffin, MD, \\ John Ehrlinger, PhD, ${ }^{\mathrm{d}}$ Eugene H. Blackstone, MD, ${ }^{\mathrm{a}, \mathrm{d}}$ Lars G. Svensson, MD, PhD,,${ }^{\mathrm{a}, \mathrm{b}}$ and \\ Bruce W. Lytle, MD
}

\section{ABSTRACT}

Background: Bicuspid aortic valves (BAV) are associated with incompletely characterized aortopathy. Our objectives were to identify distinct patterns of aortopathy using machine-learning methods and characterize their association with valve morphology and patient characteristics.

Methods: We analyzed preoperative 3-dimensional computed tomography reconstructions for 656 patients with BAV undergoing ascending aorta surgery between January 2002 and January 2014. Unsupervised partitioning around medoids was used to cluster aortic dimensions. Group differences were identified using polytomous random forest analysis.

Results: Three distinct aneurysm phenotypes were identified: $\operatorname{root}(\mathrm{n}=83 ; 13 \%)$, with predominant dilatation at sinuses of Valsalva; ascending $(n=364 ; 55 \%)$, with supracoronary enlargement rarely extending past the brachiocephalic artery; and $\operatorname{arch}(n=209 ; 32 \%)$, with aortic arch dilatation. The arch phenotype had the greatest association with right-noncoronary cusp fusion: $29 \%$, versus $13 \%$ for ascending and $15 \%$ for root phenotypes $(P<.0001)$. Severe valve regurgitation was most prevalent in root phenotype $(57 \%)$, followed by ascending $(34 \%)$ and arch phenotypes $(25 \% ; P<.0001)$. Aortic stenosis was most prevalent in arch phenotype $(62 \%)$, followed by ascending $(50 \%)$ and root phenotypes $(28 \% ; P<.0001)$. Patient age increased as the extent of aneurysm became more distal (root, 49 years; ascending, 53 years; arch, 57 years; $P<.0001$ ), and root phenotype was associated with greater male predominance compared with ascending and arch phenotypes $(94 \%, 76 \%$, and $70 \%$, respectively; $P<.0001)$. Phenotypes were visually recognizable with $94 \%$ accuracy.

Conclusions: Three distinct phenotypes of bicuspid valve-associated aortopathy were identified using machine-learning methodology. Patient characteristics and valvular dysfunction vary by phenotype, suggesting that the location of aortic pathology may be related to the underlying pathophysiology of this disease. ( $\mathrm{J}$ Thorac Cardiovasc Surg 2018;155:461-9)

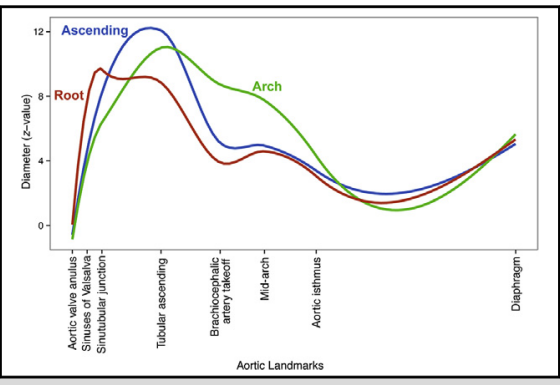

Proximal aortic aneurysm phenotype standardized diameters identified by machine learning.

\section{Central Message}

Three aortic aneurysm phenotypes-root ascending, and arch-are associated with distinct patient characteristics and thus should be taken into account in future studies on bicuspid aortopathy.

\section{Perspective}

Unsupervised clustering algorithms, applied to a large population of patients with bicuspid aortic valve-associated aortopathy, has identified 3 patterns of aortic dilatation: root, ascending, and arch. Future studies incorporating aneurysm phenotype are needed to determine whether these morphological patterns predict natural history or the need for early intervention in patients with bicuspid aortopathy.

See Editorial Commentaries pages 470 and 472.

See Editorial page 457.
As recognition of the prevalence of bicuspid aortic valve and associated aortopathy has increased over the last several decades, so too has an appreciation of substantial disparity

\footnotetext{
From the ${ }^{\mathrm{a}}$ Department of Thoracic and Cardiovascular Surgery, ${ }^{\mathrm{b}}$ Aortic Center, and ${ }^{\mathrm{e}}$ Department of Cardiovascular Medicine, Miller Family Heart and Vascular Institute; ${ }^{\mathrm{C}}$ Cleveland Clinic Lerner College of Medicine; and ${ }^{\mathrm{d}}$ Department of Quantitative Health Sciences, Research Institute, Cleveland Clinic, Cleveland, Ohio.

This study was supported in part by the Gus P. Karos Registry Fund, the David Whitmire Hearst Jr Foundation, the John and Rosemary Brown Endowed Chair in Cardiovascular Medicine, and the Kenneth Gee and Paula Shaw, $\mathrm{PhD}$, Chair in Heart Research. The statistical analysis for this work was supported in part by the National Heart, Lung and Blood Institute through Grant R01 HL103552. C.W. is a National Heart, Lung and Blood Institute Clinical Research Scholar of the
}

in the clinical presentation of these 2 often coexisting and related pathologies. A bicuspid aortic valve is responsible for approximately $50 \%$ of isolated severe aortic stenosis

Cardiothoracic Surgical Trials Network, and his Master of Science in clinical research was funded by National Institutes of Health Grant 1U01 HL088955.

Received for publication Feb 28, 2017; revisions received July 27, 2017; accepted for publication Aug 28, 2017; available ahead of print Oct 15, 2017.

Address for reprints: Eric E. Roselli, MD, Department of Thoracic and Cardiovascular Surgery, Cleveland Clinic, 9500 Euclid Ave, Desk J4-1, Cleveland, OH 44195 5108 (E-mail: roselle@ccf.org). $0022-5223 / \$ 36.00$

Copyright (C) 2017 by The American Association for Thoracic Surgery https://doi.org/10.1016/j.jtcvs.2017.08.123 

Abbreviations and Acronyms
$\mathrm{BAV}=$ bicuspid aortic valve
$\mathrm{CT}=$ computed tomography
$\mathrm{LN}=$ left-noncoronary cusp
$\mathrm{LR}=$ left-right cusp
MRI = magnetic resonance imaging
$\mathrm{RN}=$ right-noncoronary cusp
$\mathrm{TTE}=$ transthoracic echocardiography

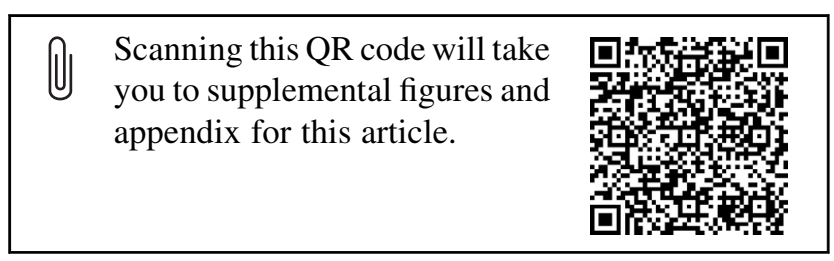

cases requiring surgery, ${ }^{1}$ and up to $56 \%$ of patients age $<30$ years with a bicuspid aortic valve have important dilatation of the proximal thoracic aorta due to heritable tissue fragility. ${ }^{2}$ The phenotypic heterogeneity of bicuspid aortopathy has long been empirically recognized by both researchers and clinicians ${ }^{3}$; however, the link between aortic morphology and valvular pathology remains incompletely characterized.

Previous classifications of aortic morphology have been based largely on 2-dimensional echocardiography or on a priori conditions to create classes of morphology. ${ }^{4-7}$ An absence of clear associations among morphology, valve dysfunction, and clinical implications has limited the appeal of such classifications. ${ }^{8}$

Pattern recognition through machine learning has been used recently in the field of genomics to stratify patients with similarly complex, multidimensional pathologies. ${ }^{9}$ In the present study, our primary objectives were to determine whether these machine-learning methods would reveal distinct patterns of aortopathy in patients with bicuspid aortic valves and, if so, to identify the valve morphology and dysfunction and patient characteristics associated with each pattern. A secondary objective was to determine whether practical visual rules can be developed based on the distinctive patterns of aortopathy identified by machine learning so that phenotypes can be recognized on imaging studies.

\section{METHODS \\ Patients}

Between January 2002 and January 2014, a total of 4856 patients underwent ascending aorta surgery at Cleveland Clinic. Of these, 821 had a bicuspid aortic valve and available preoperative cross-sectional computed tomography (CT) scans or magnetic resonance imaging (MRI). From this population, 165 patients with previous aortic surgery or ascending aortic dissection were excluded. Detailed imaging analysis was performed de novo for the remaining 656 patients.
The patients were predominantly male $(76 \% ; \mathrm{n}=500)$, and mean age at operation was $54 \pm 12$ years. Aortic regurgitation was identified preoperatively in 422 patients $(65 \%)$, of whom 222 had severe regurgitation. Aortic stenosis was identified preoperatively in 334 patients $(51 \%)$, of whom 160 had severe stenosis. Echocardiographic evidence of no or trivial valvular dysfunction was found in 97 patients $(15 \%)$.

\section{Imaging Analysis}

On 3-dimensional CT or MRI reconstructions performed preoperatively for each patient, cross-sectional diameters were measured at 8 consensus aortic landmarks ${ }^{10}$ : aortic valve annulus, sinuses of Valsalva (noncoronary cusp to right-left coronary commissure), sinutubular junction, tubular ascending aorta (aorta at the level of the pulmonary artery bifurcation), proximal aortic arch (aorta at the origin of the brachiocephalic artery), mid-aortic arch (between the left common carotid and left subclavian arteries), proximal descending thoracic aorta $(2 \mathrm{~cm}$ distal to the left subclavian artery), and aorta at diaphragm $(2 \mathrm{~cm}$ proximal to the celiac axis origin). All maximal diameters were measured from the external wall of the aorta in a plane orthonormal to the centerline of flow.

\section{Clinical Data}

Bicuspid aortic valve morphology was determined by intraoperative inspection and categorized by bicuspid fusion pattern and number of raphae. ${ }^{11}$ When not sufficiently documented in the operative notes, valve morphology was obtained from preoperative echocardiograms. Patientlevel preoperative and echocardiographic variables were retrieved from prospective databases. The Cleveland Clinic's Institutional Review Board approved the study and use of all data for research, and waived the requirement for patient consent.

\section{Data Analysis}

Cluster analysis. In preparation for pattern analysis, cross-sectional diameters at each landmark were first standardized ( $z$-value) for body surface area using normal diameters from a population of healthy individuals. ${ }^{12}$ Standardization in this manner allowed for the assessment of aortic shape rather than absolute diameter, which varies by body size. Furthermore, by using diameters from healthy young adults, standardization is not confounded by degenerative dilatation associated with age. The proximal 5 diameters were chosen for analysis because the pathology of interest (aneurysm) occurs in the ascending aorta, and more distal landmarks are subject to confounding pathologies, such as coarctation and descending aorta arteriosclerotic disease.

Incorporating these proximal 5 standardized diameters, we calculated a dissimilarity matrix using Pearson correlation measures (Figure E1). Partitioning around medoids was then applied to the matrix to cluster patients in an unsupervised manner. ${ }^{13}$ Average silhouette width was used to identify the optimal number of clusters. Within each cluster of patients so identified, the resulting patterns of aortic $z$-values were then characterized as distinct phenotypes.

Visual classification. The clustering and resulting phenotypic characterization of aortic dimensions allowed us to suggest rules for visual phenotypic classification of a given aorta. All CT or MRI scans were then re-reviewed without knowledge of the cluster to which the aorta had been assigned by machine learning, and the visual and machine-learning classifications were compared.

Characterization of patients within aortic phenotypes. Comparisons were made to assess differences in aortic valve morphology and dysfunction and patient characteristics among aortic phenotypes. For this, a polytomous random forest ${ }^{14-16}$ classification model for the probability of phenotype membership was created, taking into account 56 patient-level preoperative and echocardiographic variables, not including the CT/MRI dimensions used in clustering (Appendix E1). A variable importance measure quantified the contribution of each variable to 
classification accuracy. ${ }^{14,17}$ The probabilities of phenotype membership adjusted for these 56 variables are presented as partial dependency plots. ${ }^{16}$ Software used. Clustering was performed using the "cluster" package, ${ }^{18}$ and random forest classification analysis was performed using the "randomForestSRC" package ${ }^{15}$ in R version 3.0.2. ${ }^{19}$ Other comparisons were performed using SAS version 9.1 (SAS Institute, Cary, NC).

Managing missing data. Missing data were imputed using the random forest imputation method of Ishwaran and colleagues. ${ }^{20}$ Before splitting a node, missing data for a variable were imputed by randomly drawing values from nonmissing data. The purpose of imputing these data was to make it possible to assign cases to daughter nodes in the event that the node was split on a variable with missing data. Imputed data were not used to calculate the split statistic, which used nonmissing data only. Following a node split, imputed data were reset to missing, and the process was repeated until terminal nodes were reached. Imputation was done using a maximal class rule for integer-valued variables and a mean rule for continuous variables.

Presentation. Continuous variables are summarized as mean \pm standard deviation, and pairwise comparisons were performed using the Wilcoxon rank-sum test. Categorical data are summarized by frequencies and percentages, and comparisons were performed using the $\chi^{2}$ test.

\section{RESULTS}

\section{Aortic Dimensions}

In general, aortic dimensions through the origin of the celiac axis were greater than expected in a normal population. The mean tubular ascending aorta diameter was $48 \pm 6.6 \mathrm{~mm}$, corresponding to a $z$-value of $11 \pm 3.3$ standard deviations greater than normal.

\section{Aortic Phenotypes}

A 3-phenotype solution yielded the highest average silhouette width $(S=0.44$; Figure 1$)$. The dimensional pattern of aortopathy expressed by each phenotype so identified varied substantially (Figure 2 and Figure E2). The pattern with a more proximal aneurysm involving the sinuses of Valsalva was termed the root phenotype, a tubular ascending aneurysm pattern was termed the ascending phenotype, and a more distal pattern of dilatation was termed the arch phenotype.

The root phenotype was characterized by maximum $z$-value at the sinutubular junction $(9.7 \pm 3.8 z)$, with tapering of the aneurysm in the tubular ascending aorta (Table 1). The ascending phenotype exhibited a maximum $z$-value at the tubular ascending aorta $(12 \pm 3.2 z)$, with the aneurysm rapidly tapering proximal to the takeoff of the brachiocephalic artery $(5.1 \pm 2.2 z)$. The arch phenotype also showed a maximum $z$-value at the tubular ascending aorta $(11 \pm 2.8 z)$; however, it was characterized by persistent dilatation through the takeoff of the brachiocephalic artery $(8.7 \pm 3.0 z)$ into the aortic arch $(7.8 \pm 3.7 z)$.

\section{Aortic Valve and Patient Characteristics by Phenotype}

A left-right cusp fusion pattern was equally prevalent in both the root and ascending phenotypes $(74 \%$ and $73 \%$, respectively; $P>9$ ), as was a right-noncoronary cusp fusion pattern $(15 \%$ and $13 \%$, respectively; $P=.9)$ (Table 1). Compared with the 2 more proximal phenotypes, the arch phenotype was less commonly associated with a left-right fusion pattern (56\% vs $74 \%$ and $73 \%)$ and more commonly associated with a right-noncoronary pattern ( $29 \%$ vs $15 \%$ and $13 \%)$. There was no statistically significant difference in the distribution of Sievers type 0 valve morphology among the 3 phenotypes; however, the prevalence of patients with Sievers type 0 valve morphology in this population of patients is inherently low.

In general, the degree of aortic stenosis was most predictive of ascending and arch phenotype membership, and the degree of aortic valve regurgitation was most predictive of root phenotype membership (Figure E3). Severe aortic regurgitation was present in $57 \%$ of patients with the root phenotype, and was less prevalent with more distal aneurysm location (ascending, 34\%; arch, 25\%). Younger patients with aortic regurgitation had a higher probability of root phenotype membership. As patients grew older and the degree of aortic stenosis became more severe, the probability of membership in the arch phenotype increased (Figure 3). Specifically, aortic stenosis was present in $62 \%$ of patients with the arch phenotype, in $50 \%$ of those with the ascending phenotype, and in $28 \%$ of those with the root phenotype, and this relationship persisted when stenosis became severe $(44 \%, 24 \%$, and $12 \%$, respectively). Mean and peak aortic valve gradients followed this decreasing trend as the extent of aneurysm became more proximal.

Male predominance $(94 \%)$ ) characterized the root phenotype more than the ascending and arch phenotypes $(76 \%$ and $70 \%$, respectively; Table 1). Patients with the root phenotype were the tallest. The root and arch phenotypes

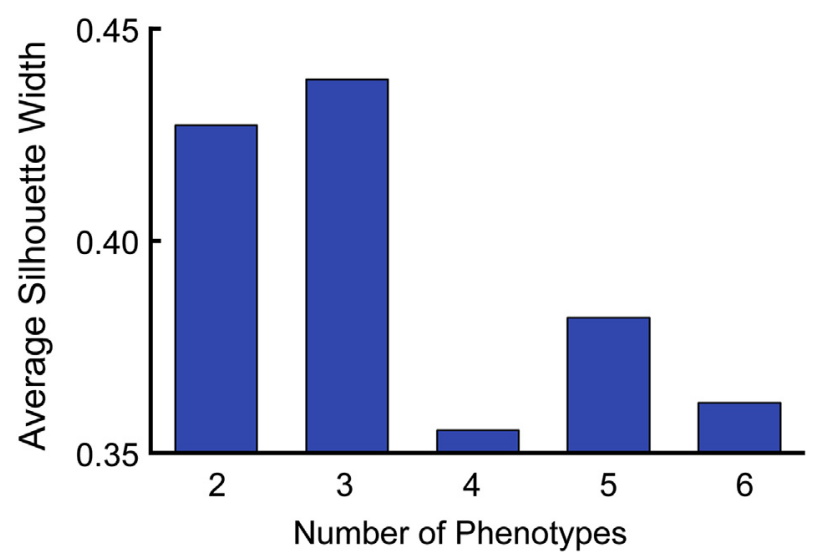

FIGURE 1. Average silhouette width by solutions with differing numbers of clusters. The average silhouette width is a measure of distance showing which aortic morphologies lie well within the cluster and which ones merely hold an intermediate position; it is used to determine the optimal number of clusters. 

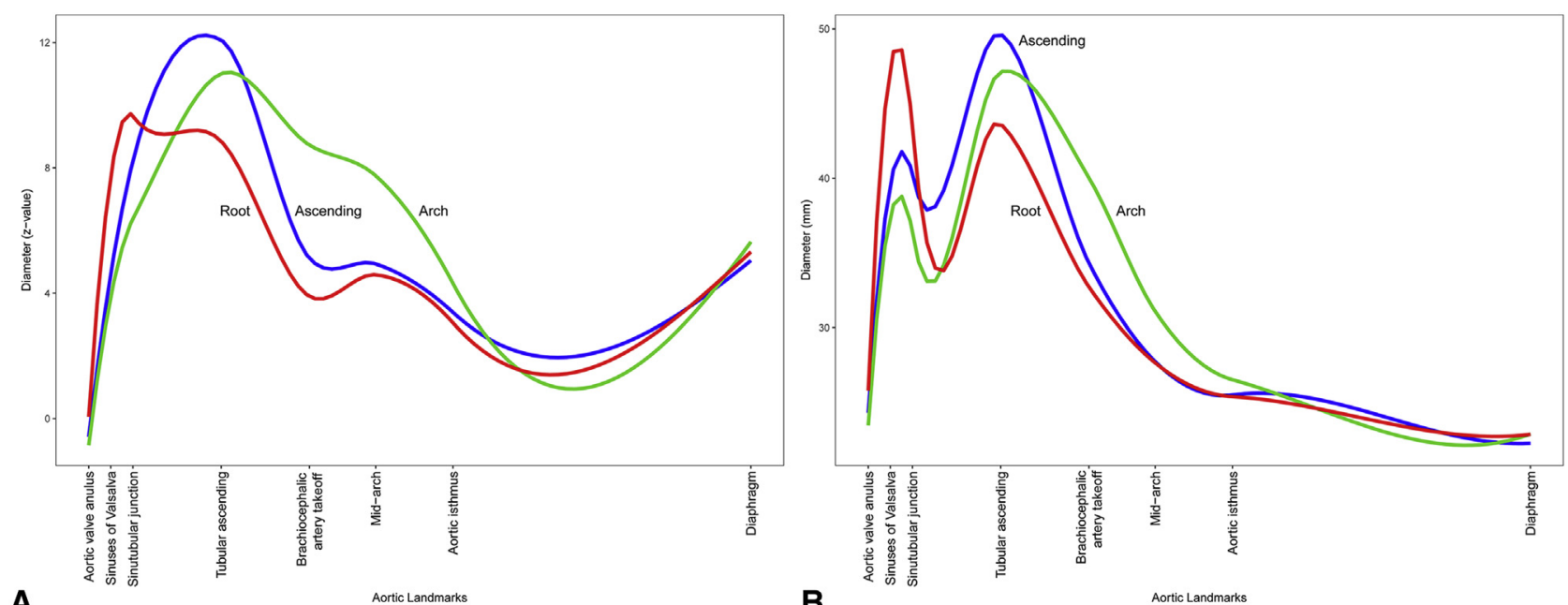

A

FIGURE 2. Aortic diagram of bicuspid aortic valve-associated aneurysm phenotypes. The distance between landmarks is the average distance along the centerline of flow between each landmark. Root phenotype is characterized by maximal dilatation at sinuses of Valsalva and sinutubular junction. Arch phenotype is the only phenotype with a diameter at brachiocephalic takeoff greater than or equal to the diameter at the sinutubular junction. Averages are displayed using a smoothing spline ( $\mathrm{R}$ statistical software $\left.{ }^{20}\right)$. A, The vertical axis represents standardized values $(z)$ at each aortic landmark. B, The vertical axis represents aortic diameter in millimeters.

frequently exhibited opposite direction of many associations in reference to the ascending phenotype (Figure E4). However, the 3 groups were not significantly different in terms of preoperative comorbidities, including hypertension, smoking, diabetes, heart failure, ejection fraction, and stroke $(P>.10)$.

\section{Visual Versus Machine-Learning Classification}

The phenotypes identified by unsupervised clustering suggest a set of rules that may be applicable for visual classification based on CT or MRI images: (1) If the aorta at the sinuses of Valsalva is larger than at the tubular ascending aorta, classify as root phenotype; (2) among the remaining unclassified patients, if the aorta at the origin of the brachiocephalic artery is smaller than at the sinutubular junction, classify as ascending phenotype; (3) if the aorta at the origin of the brachiocephalic artery is equal to or larger than at the sinutubular junction, classify as arch phenotype.

Figure 4 shows how the 3 phenotypes identified by unsupervised clustering relate to differences in $z$-values between aortic landmarks that were embodied in these visual classification rules. The concordance between unsupervised clustering phenotype and visual classification by these rules was $94 \%$ (Table 2).

\section{DISCUSSION \\ Principal Findings}

Unsupervised clustering identified 3 distinct phenotypes of bicuspid aortic valve-associated aortopathy: root, ascending, and arch. Each phenotype was associated with distinct clinical findings, which may be helpful in clinical decision making and useful in future studies of this disease process (Figure 5). The use of this machine-learning technology is not necessary for incorporating the characteristic of bicuspid aortopathy phenotype into future analyses; by applying simple visual classification rules derived from the clustering analysis, we were able to obtain excellent concordance with the machine-learning results.

\section{Findings in Context}

As our understanding of bicuspid aortic valve and associated aortopathy has grown, the inextricable relationship between these pathologies has become increasingly complex. The existence of distinct phenotypes of bicuspid aortic valve-associated aneurysm has been documented by others. ${ }^{4-7}$ A recent literature review by Verma and $\mathrm{Siu}^{3}$ identified the same 3 phenotypes that we found by machine learning based on an amalgamation of the available literature; however, no individual study cited recognized all 3 phenotypes. Our purpose in performing this analysis was to provide an unbiased determination of phenotype based on unsupervised machine-learning methodology and to display the clinical characteristics of patients presenting with each phenotype so identified.

Patients with ascending and arch phenotypes share many similarities, suggesting a strong hemodynamic underpinning. Indeed, a 2-phenotype classification emerged as second best to 3 phenotypes (Figure 1). In line with a recent study, the right-noncoronary cusp fusion pattern was more common in the arch phenotype. ${ }^{21}$ In addition, several 4-dimensional MRI hemodynamic studies have shown that right-noncoronary cusp fusion is associated with left-sided helical flow, with the greatest wall stress along the lesser curve of the aorta. ${ }^{22,23}$ We noted that as the extent of 
TABLE 1. Patient characteristics by aortic phenotype

\begin{tabular}{|c|c|c|c|c|c|c|c|}
\hline Characteristic & n* & $\begin{array}{c}\text { Root } \\
(n=83)\end{array}$ & $\mathbf{n}^{*}$ & $\begin{array}{c}\text { Ascending } \\
(\mathrm{n}=364)\end{array}$ & $\mathbf{n}^{*}$ & $\begin{array}{c}\text { Arch } \\
(n=209)\end{array}$ & $P$ value \\
\hline \multicolumn{8}{|l|}{ Demographics } \\
\hline Female, n (\%) & 83 & $5(6.0)$ & 364 & $88(24)$ & 209 & $63(30)$ & $<.0001$ \\
\hline Age, $y$, mean \pm SD & 83 & $49 \pm 12$ & 364 & $53 \pm 12$ & 209 & $57 \pm 12$ & $<.0001$ \\
\hline Height, $\mathrm{cm}$, mean $\pm \mathrm{SD}$ & 83 & $180 \pm 7.9$ & 364 & $175 \pm 10$ & 209 & $173 \pm 10$ & $<.0001$ \\
\hline Weight, $\mathrm{kg}$, mean $\pm \mathrm{SD}$ & 83 & $94 \pm 21$ & 364 & $90 \pm 19$ & 209 & $86 \pm 18$ & .01 \\
\hline Body surface area, $\mathrm{m}^{2}$, mean $\pm \mathrm{SD}$ & 83 & $2.2 \pm 0.27$ & 364 & $2.1 \pm 0.26$ & 209 & $2.0 \pm 0.25$ & .004 \\
\hline \multicolumn{8}{|l|}{ Bicuspid valve classification, $\mathrm{n}(\%)$} \\
\hline \multicolumn{8}{|l|}{ Type 0} \\
\hline Anterior-posterior & 74 & $1(1.4)$ & 319 & $1(0.31)$ & 170 & $2(1.2)$ & .4 \\
\hline Lateral & 74 & $3(4.1)$ & 319 & $8(2.5)$ & 170 & $1(0.59)$ & .18 \\
\hline \multicolumn{8}{|l|}{ Type I } \\
\hline LR & 74 & $55(74)$ & 319 & $234(73)$ & 170 & $95(56)$ & .0002 \\
\hline $\mathrm{RN}$ & 74 & $11(15)$ & 319 & $43(13)$ & 170 & $50(29)$ & $<.0001$ \\
\hline $\mathrm{LN}$ & 74 & $0(0)$ & 319 & $3(0.94)$ & 170 & $1(0.59)$ & .7 \\
\hline \multicolumn{8}{|l|}{ Type II } \\
\hline LR-RN & 74 & $3(4.1)$ & 319 & $25(7.8)$ & 170 & $18(11)$ & $<.0001$ \\
\hline LR-LN & 74 & $1(1.4)$ & 319 & $4(1.3)$ & 170 & $3(1.8)$ & .9 \\
\hline LN-RN & 74 & $0(0)$ & 319 & $1(0.31)$ & 170 & $0(0)$ & .7 \\
\hline \multicolumn{8}{|l|}{ Aortic valve function } \\
\hline Aortic stenosis, n (\%) & 83 & $23(28)$ & 364 & $181(50)$ & 209 & $130(62)$ & $<.0001$ \\
\hline Severe stenosis, $\mathrm{n}(\%)$ & 78 & $9(12)$ & 316 & $75(24)$ & 174 & $76(44)$ & $<.0001$ \\
\hline Aortic valve area, $\mathrm{cm}^{2}$, mean $\pm \mathrm{SD}$ & 25 & $1.29 \pm 0.60$ & 195 & $1.06 \pm 0.46$ & 153 & $0.91 \pm 0.38$ & $<.0001$ \\
\hline Peak aortic valve gradient, $\mathrm{mm} \mathrm{Hg}$, mean $\pm \mathrm{SD}$ & 50 & $40 \pm 32$ & 295 & $49 \pm 34$ & 185 & $65 \pm 36$ & $<.0001$ \\
\hline Mean aortic valve gradient, $\mathrm{mm} \mathrm{Hg}$, mean $\pm \mathrm{SD}$ & 49 & $23 \pm 19$ & 293 & $28 \pm 21$ & 183 & $37 \pm 21$ & $<.0001$ \\
\hline Aortic regurgitation, $\mathrm{n}(\%)$ & 83 & $66(80)$ & 364 & $238(65)$ & 209 & $118(56)$ & .0008 \\
\hline Severe regurgitation, $\mathrm{n}(\%)$ & 83 & $47(57)$ & 362 & $123(34)$ & 205 & $52(25)$ & $<.0001$ \\
\hline \multicolumn{8}{|l|}{ Aortic measurements, mm, mean $\pm \mathrm{SD}$} \\
\hline Aortic valve annulus & 83 & $26 \pm 4.3$ & 364 & $24 \pm 4.1$ & 209 & $24 \pm 3.7$ & $<.0001$ \\
\hline Sinuses of Valsalva & 83 & $48 \pm 6.0$ & 364 & $40 \pm 5.1$ & 209 & $38 \pm 5.1$ & $<.0001$ \\
\hline Sinutubular junction & 83 & $43 \pm 7.6$ & 364 & $40 \pm 5.9$ & 209 & $36 \pm 5.1$ & $<.0001$ \\
\hline Tubular ascending & 83 & $44 \pm 6.8$ & 364 & $50 \pm 6.5$ & 209 & $47 \pm 5.7$ & $<.0001$ \\
\hline Brachiocephalic takeoff & 83 & $33 \pm 4.5$ & 364 & $34 \pm 4.0$ & 209 & $40 \pm 5.0$ & $<.0001$ \\
\hline Mid-arch & 83 & $28 \pm 4.4$ & 364 & $28 \pm 3.8$ & 209 & $31 \pm 5.0$ & $<.0001$ \\
\hline Proximal descending & 83 & $25 \pm 4.1$ & 364 & $26 \pm 4.2$ & 209 & $26 \pm 4.6$ & .01 \\
\hline Distal descending & 72 & $23 \pm 3.3$ & 294 & $22 \pm 3.3$ & 167 & $23 \pm 4.1$ & .2 \\
\hline \multicolumn{8}{|l|}{ Aortic measurements, $z$-value, mean $\pm \mathrm{SD}$} \\
\hline Aortic valve annulus & 83 & $0.06 \pm 2.5$ & 364 & $-0.58 \pm 2.5$ & 209 & $-0.85 \pm 2.3$ & .01 \\
\hline Sinuses of Valsalva & 83 & $7.8 \pm 2.4$ & 364 & $4.6 \pm 2.1$ & 209 & $3.9 \pm 2.0$ & $<.0001$ \\
\hline Sinotubular junction & 83 & $9.7 \pm 3.8$ & 364 & $8.2 \pm 3.0$ & 209 & $6.4 \pm 2.6$ & $<.0001$ \\
\hline Tubular ascending & 83 & $8.8 \pm 3.2$ & 364 & $12 \pm 3.2$ & 209 & $11 \pm 2.8$ & $<.0001$ \\
\hline Brachiocephalic takeoff & 83 & $3.9 \pm 2.6$ & 364 & $5.1 \pm 2.2$ & 209 & $8.7 \pm 3.0$ & $<.0001$ \\
\hline Mid-arch & 83 & $4.6 \pm 3.3$ & 364 & $4.9 \pm 2.7$ & 209 & $7.8 \pm 3.7$ & $<.0001$ \\
\hline Proximal descending & 83 & $3.1 \pm 2.8$ & 364 & $3.4 \pm 2.9$ & 209 & $4.3 \pm 2.9$ & $<.0001$ \\
\hline Distal descending & 72 & $5.3 \pm 2.4$ & 294 & $5.0 \pm 2.3$ & 167 & $5.6 \pm 2.8$ & .12 \\
\hline \multicolumn{8}{|l|}{ Comorbidities } \\
\hline Ejection fraction, $\%$, mean $\pm \mathrm{SD}$ & 83 & $56 \pm 6.6$ & 361 & $56 \pm 7.8$ & 207 & $57 \pm 6.7$ & .18 \\
\hline Hypertension, $\mathrm{n}(\%)$ & 83 & $46(55)$ & 364 & $196(54)$ & 209 & $122(58)$ & .6 \\
\hline Smoking, $\mathrm{n}(\%)$ & 83 & $28(34)$ & 364 & $150(41)$ & 208 & $97(47)$ & .12 \\
\hline Diabetes, n (\%) & 83 & $6(7.2)$ & 361 & $22(6.1)$ & 207 & $20(9.7)$ & .3 \\
\hline Heart failure, $\mathrm{n}(\%)$ & 83 & $3(3.6)$ & 364 & $19(5.2)$ & 209 & $12(5.7)$ & .8 \\
\hline Stroke, $\mathrm{n}(\%)$ & 83 & $1(1.2)$ & 364 & $12(3.3)$ & 209 & $12(5.7)$ & .14 \\
\hline
\end{tabular}


TABLE 1. Continued

\begin{tabular}{|c|c|c|c|c|c|c|c|}
\hline Characteristic & $\mathbf{n} *$ & $\begin{array}{c}\text { Root } \\
(\mathbf{n}=\mathbf{8 3})\end{array}$ & $\mathbf{n}^{*}$ & $\begin{array}{c}\text { Ascending } \\
(n=364)\end{array}$ & n* & $\begin{array}{c}\text { Arch } \\
(\mathbf{n}=\mathbf{2 0 9})\end{array}$ & $P$ value \\
\hline \multicolumn{8}{|l|}{ Procedure details, n (\%) } \\
\hline Aortic valve replacement & 83 & $59(71)$ & 364 & $239(66)$ & 209 & $172(82)$ & .0001 \\
\hline Aortic valve repair & 83 & $21(25)$ & 364 & $90(25)$ & 209 & $26(12)$ & .001 \\
\hline No valve intervention & 83 & $3(3.6)$ & 364 & $35(9.6)$ & 209 & $11(5.3)$ & .06 \\
\hline Hypothermic circulatory arrest required & 83 & $14(17)$ & 364 & $101(28)$ & 209 & $84(40)$ & .0001 \\
\hline
\end{tabular}

$S D$, Standard deviation; $L R$, left-right cusp; $R N$, right-noncoronary cusp; $L N$, left-noncoronary cusp. *Patients with available data.

aneurysm became more distal, the degree of aortic stenosis and resultant hemodynamic stresses were greater. Patients with the arch phenotype were older, suggesting that prolonged exposure to the hemodynamic stress from a stenotic bicuspid valve may contribute to more distal disease. The striking similarity of effect between age and aortic stenosis as they relate to probability of group membership (see Figure 5) implies that arch phenotype may be a progressive form of aortopathy related more to altered hemodynamics than to a genetically associated cause.

The strong association of male sex, young age, and severe aortic regurgitation in patients with the root phenotype suggests a predisposition toward a more aggressive form of aortopathy strongly indicative of a genetic connective tissue disorder-associated etiology. Studies advocating a genetic etiology for dilatation are based mostly on young adults and pediatric patients, ${ }^{24}$ who have a higher prevalence of the root phenotype than older patients. A study of young adults with bicuspid aortic valve and no evidence of valvular dysfunction found that those with dilatation had the greatest aortic diameter at the sinuses of Valsalva. ${ }^{24}$ Furthermore, patients with the root phenotype undergoing isolated aortic valve replacement for regurgitation are at

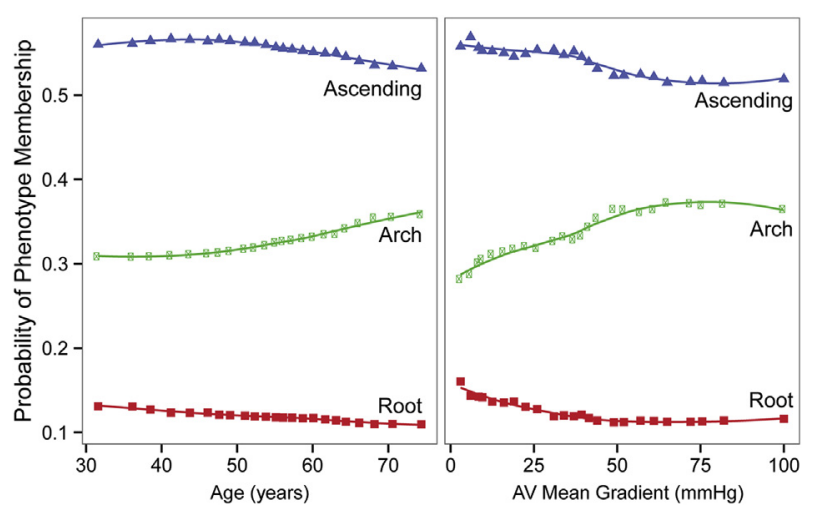

FIGURE 3. Partial dependency plot of phenotype membership related to age and aortic valve $(A V)$ mean gradient. Each point is located along the horizontal axis evenly along the distribution of all patient values for that variable and represents the covariate-adjusted probability of membership in each of the 3 identified phenotypes: root (red), ascending (blue), and $\operatorname{arch}$ (green). The Loess smooth curve indicates the trend of this relationship. greater risk of continued aortic growth compared with those with more distal phenotypes characterized predominantly by aortic valve stenosis. ${ }^{25}$ Patients with the root phenotype and aortic regurgitation undergoing valve-sparing root replacement have survival and freedom from reoperation equal to those of patients with tricuspid valves, suggesting that inherent aortic wall weakness and resultant dilatation of the aortic valve complex, rather than intrinsic valve dysfunction, is the driving force for regurgitation. ${ }^{26}$ In our study, the root phenotype was most common in young males with predominantly aortic regurgitation, suggesting a divergent pathophysiology from that of ascending and arch phenotypes.

\section{Methodological Considerations}

The machine-learning methodology used in our study did not involve prespecified thresholds or criteria for clustering (so-called unsupervised clustering). By standardizing for body surface area using normal diameters from a population of healthy individuals, the clustering focused on the extent of aneurysm directly attributable to the presence of a bicuspid aortic valve, and not to anthropomorphic variations in aortic size. This yielded an unbiased, unsupervised classification of aortic phenotype based on data-driven similarities in aortic configuration.

Many early methodologies relied on transthoracic echocardiographic (TTE) measurement of the ascending aorta. TTE-based aortic imaging is often limited to the proximal ascending aorta, which precludes distal ascending and proximal arch measurement. Moreover, compared with proximal ascending landmarks, measurements at the aortic arch have worse correlation with CT and MRI measurements and greater interobserver and intraobserver variabilities. ${ }^{27}$ Classifications by Schaefer and colleagues ${ }^{4}$ and Jackson and colleagues ${ }^{5}$ used echocardiographic aortic imaging, which likely accounts for their failure to identify a more distal aneurysm phenotype.

In a semisupervised fashion, Fazel and colleagues first identified 4 patterns of aortopathy using hierarchical agglomerative clustering applied to cross-sectional CT measurements of 64 patients, ${ }^{6}$ and later updated the classification with a fifth pattern. ${ }^{28}$ Although their approach to clustering could be criticized for the use of within-patient 


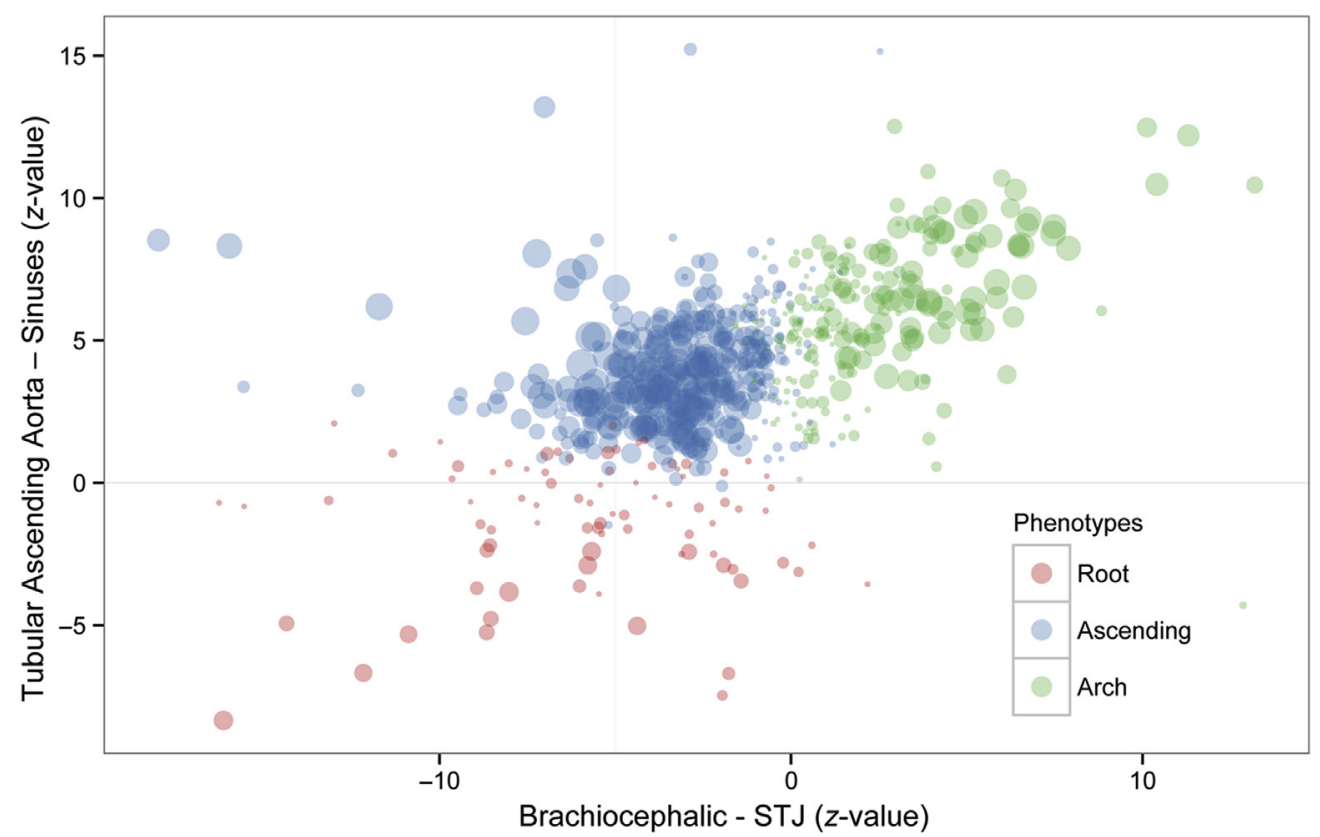

FIGURE 4. Graphical representation of unsupervised clustering results and proximity measures as they relate to rules for visual classification. Each patient is shown as a point colored by clustering assignment: root (red), ascending (blue), and arch (green). Point size is related to silhouette width, a measure of group membership. The horizontal axis demonstrates values for the sinutubular junction (STJ) $z$-value subtracted from the brachiocephalic $z$-value. The vertical axis shows the sinuses of Valsalva $z$-value subtracted from the average of the ascending and brachiocephalic $z$-values, the latter reflecting size of the tubular ascending aorta.

standardization and an arbitrary determination of the number of clusters, they identified a high prevalence of arch aneurysms. Their determination of 2 additional phenotypes may be related to the difference in clustering methodology and the small number of patients in their study.

\section{Clinical Implications}

At our institution, the aortopathy phenotype dictates the extent of resection in patients requiring surgical intervention for ascending aortic aneurysm. The root phenotype necessitates root replacement - often with valve preservation and repair, because the majority present with aortic regurgitation rather than stenosis. We recognize the controversy surrounding how to best manage the aortic root in patients with bicuspid aortopathy. The finding that root phenotype

TABLE 2. Comparison of clustering assignment (phenotype) and visual classifications

\begin{tabular}{lccc}
\hline & \multicolumn{3}{c}{ Clustering assignment } \\
\cline { 2 - 4 } Visual classification & $\begin{array}{c}\text { Root } \\
\text { No. }(\% \text { of } \mathbf{8 3})\end{array}$ & $\begin{array}{c}\text { Ascending } \\
\text { No. }(\% \text { of } 364)\end{array}$ & $\begin{array}{c}\text { Arch } \\
\text { No. }(\% \text { of 209) }\end{array}$ \\
\hline Root phenotype & $\mathbf{7 7}(\mathbf{9 3})$ & $3(0.82)$ & $0(0)$ \\
Ascending phenotype & $5(6.0)$ & $\mathbf{3 4 0}(\mathbf{9 3})$ & $11(5.3)$ \\
Arch phenotype & $1(1.2)$ & $21(5.8)$ & $\mathbf{1 9 8}(\mathbf{9 5})$ \\
\hline
\end{tabular}

Concordant classification shown in bold from top left to bottom right. Overall concordance in classification was $94 \%$. is more common in young patients predisposes them to a prolonged treatment history. Many believe that the benefits of a valve-sparing approach to aortic root replacement with annulus stabilization are greatest for these young, active individuals, ${ }^{29,30}$ whereas others advocate root and valve replacement with a mechanical prosthesis, which requires lifelong anticoagulation and carries its own inherent risks. ${ }^{31}$

Controversy has arisen about managing the arch in patients with bicuspid aortopathy, with some recommending judicious use of circulatory arrest because of the low risk of late arch dilatation and concerns for associated morbidity risk, ${ }^{32}$ and others recommending more liberal use of circulatory arrest, especially in young patients, because of concerns about late aneurysmal degeneration of residual diseased aorta. ${ }^{33,34}$ The finding that patients with the arch phenotype who may need hypothermic circulatory arrest to adequately resect the aneurysmal aorta tend to be older further compounds the risk associated with circulatory arrest. ${ }^{35}$

Future functional aortic flow studies should take into account these aortic phenotypes to improve our understanding of underlying pathophysiology. Longitudinal studies incorporating bicuspid aortopathy phenotype are needed to determine whether these morphological patterns predict natural history or the need for early intervention.

\section{Study Strengths and Limitations}

This analysis is limited by its cross-sectional view of a lifelong, progressive pathology. The apparent progression 


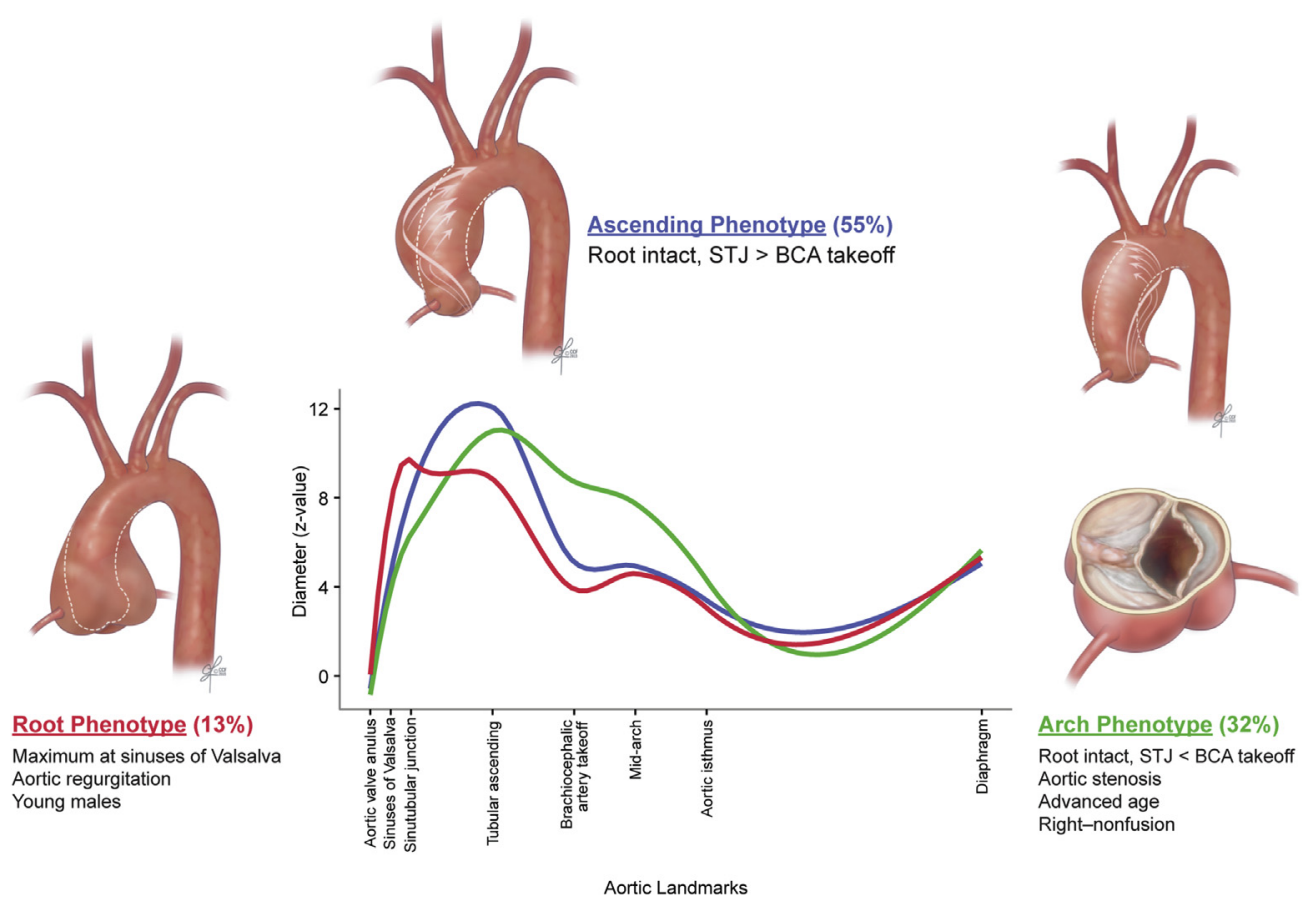

FIGURE 5. Aortic diagram of bicuspid aortic valve-associated aneurysm phenotypes with schematic representation of each phenotype and clinical and pathologic associations. STJ, Sinutubular junction; $B C A$, brachiocephalic artery.

from ascending to arch phenotype with age also suggests a more continuous phenotypic spectrum rather than distinct phenotypes, which may be why a 2-phenotype model has an average silhouette width nearly equivalent to a 3 -phenotype model. Identifying the true relationship between ascending and arch phenotypes will require longitudinal data.

All of our patients had advanced aortopathy requiring surgical ascending aorta replacement, and might not be representative of all patients with a bicuspid aortic valve, particularly in terms of how clinicians care for and follow patients with different aortic phenotypes early in the natural history of the disease. Identifying and studying a large group of patients with bicuspid disease may help address this bias in future studies.

In this study, we included Sievers type 0, I, and II bicuspid valves. Some have argued against this classification, but in particular, the number of patients with unicuspid valves is small.

As has been suggested by Bulmer, ${ }^{36}$ the aortic valve annulus is approximately symmetric $(-0.25)$. The sinuses of Valsalva (0.67), sinutubular junction (0.59), tubular ascending (0.73), and brachiocephalic takeoff (0.56) are moderately asymmetric, and thus a single aortic diameter measurement might not completely represent each aortic landmark.

The use of clustering methodology is not simple to reproduce and requires a substantial population of heterogeneous patients to assign each patient to a group. However, a strength of our study is that the unsupervised analysis has yielded aortic phenotype descriptors that are sufficiently distinct to be reliably recognized by rather simple visual rules.

\section{CONCLUSIONS}

Using an unsupervised machine-learning approach in a large group of surgically treated patients with bicuspid aortic valve, we identified 3 distinct phenotypes of bicuspid aortopathy: root, ascending, and arch. The fact that patients with root phenotype are younger and almost exclusively male suggests a genetic etiology for root aneurysms. The arch phenotype appears to be related to severe aortic stenosis and advanced patient age, pointing to a hemodynamically mediated process. Given the strong evidence for differing pathophysiologic underpinnings of disease, aneurysm phenotype should be taken into account in future studies attempting to elucidate the relationship between a bicuspid aortic valve and aortopathy.

\section{Conflict of Interest Statement}

Authors have nothing to disclose with regard to commercial support.

\section{References}

1. Roberts WC, Ko JM. Frequency by decades of unicuspid, bicuspid, and tricuspid aortic valves in adults having isolated aortic valve replacement for aortic stenosis, with or without associated aortic regurgitation. Circulation. 2005;111:920-5.

2. Ward C. Clinical significance of the bicuspid aortic valve. Heart. 2000;83:81-5. 
3. Verma S, Siu SC. Aortic dilatation in patients with bicuspid aortic valve. $N$ Engl J Med. 2014;370:1920-9.

4. Schaefer BM, Lewin MB, Stout KK, Gill E, Prueitt A, Byers PH, et al. The bicuspid aortic valve: an integrated phenotypic classification of leaflet morphology and aortic root shape. Heart. 2008;94:1634-8.

5. Jackson V, Petrini J, Caidahl K, Eriksson MJ, Liska J, Eriksson P, et al. Corrigendum to Bicuspid aortic valve leaflet morphology in relation to aortic root morphology: a study of 300 patients undergoing open-heart surgery. Eur J Cardiothorac Surg. 2012;41:471.

6. Fazel SS, Mallidi HR, Lee RS, Sheehan MP, Liang D, Fleischman D, et al. The aortopathy of bicuspid aortic valve disease has distinctive patterns and usually involves the transverse aortic arch. J Thorac Cardiovasc Surg. 2008;135:901-7.

7. Girdauskas E, Borger MA, Secknus MA, Girdauskas G, Kuntze T. Is aortopathy in bicuspid aortic valve disease a congenital defect or a result of abnormal hemodynamics? A critical reappraisal of a one-sided argument. Eur J Cardiothorac Surg. 2011;39:809-14.

8. Della Corte A, Bancone C. Multiple aortopathy phenotypes with bicuspid aortic valve: the importance of terminology and definition criteria. Eur J Cardiothorac Surg. 2012;41:1404.

9. ENCODE Project Consortium Collaborators (594). An integrated encyclopedia of DNA elements in the human genome. Nature. 2012;489:57-74.

10. Hiratzka LF, Bakris GL, Beckman JA, Bersin RM, Carr VF, Casey DE Jr, et al. 2010 ACCF/AHA/AATS/ACR/ASA/SCA/SCAI/SIR/STS/SVM guidelines for the diagnosis and management of patients with thoracic aortic disease: a report of the American College of Cardiology Foundation/American Heart Association Task Force on Practice Guidelines, American Association for Thoracic Surgery, American College of Radiology, American Stroke Association, Society of Cardiovascular Anesthesiologists, Society for Cardiovascular Angiography and Interventions, Society of Interventional Radiology, Society of Thoracic Surgeons, and Society for Vascular Medicine. Circulation. 2010;121:e266-369.

11. Sievers HH, Schmidtke C. A classification system for the bicuspid aortic valve from 304 surgical specimens. J Thorac Cardiovasc Surg. 2007;133:1226-33.

12. Kaiser T, Kellenberger CJ, Albisetti M, Bergsträsser E, Valsangiacomo Buechel ER. Normal values for aortic diameters in children and adolescents: assessment in vivo by contrast-enhanced CMR-angiography. J Cardiovasc Magn Reson. 2008;10:56.

13. Kaufman L, Rousseeuw PJ. Finding Groups in Data: an Introduction to Cluster Analysis. Hoboken, NJ: Wiley; 2005.

14. Breiman L. Random forests. Machine Learn. 2001;45:5-32.

15. Ishwaran H, Kogalur UB. Random forests for survival, regression, and classification (RF-SRC), R package version 1.6.0, Available at: http://cran.r-project.org/ web/packages/randomForestSRC/index.html. Accessed February 27, 2015.

16. Ehrlinger J. ggRandomForests: visually exploring Random Forests. R package version 1.1.4. Available at: http://cran.r-project.org/package $=$ ggRandomForests. Accessed February 27, 2015.

17. Breiman L, Friedman JH, Olshen RA, Stone CJ. Classification and Regression Trees. Boca Raton, FL: Chapman \& Hall/CRC; 1984.

18. Maechler M, Rousseeuw PJ, Struyf A, Hubert M, Hornik K. 2013. Cluster: cluster analysis basics and extensions. $\mathrm{R}$ package version 1.14.4.

19. R Development Core Team. $R$ : a language and environment for statistical computing. Version 3.3.1. Vienna, Austria: R Foundation for Statistical Computing; 2016. Available at: http://www.R-project.org. Accessed June 21, 2016.

20. Ishwaran H, Kogalur UB, Blackstone EH, Lauer MS. Random survival forests. Ann Appl Stat. 2008;2:841-60.
21. Merritt BA, Turin A, Markl M, Malaisrie SC, McCarthy PM, Carr JC. Association between leaflet fusion pattern and thoracic aorta morphology in patients with bicuspid aortic valve. J Magn Reson Imaging. 2014;40:294-300.

22. Barker AJ, Markl M, Bürk J, Lorenz R, Bock J, Bauer S, et al. Bicuspid aortic valve is associated with altered wall shear stress in the ascending aorta. Circ Cardiovasc Imaging. 2012;5:457-66.

23. Hope MD, Hope TA, Meadows AK, Ordovas KG, Urbania TH, Alley MT, et al. Bicuspid aortic valve: four-dimensional MR evaluation of ascending aortic systolic flow patterns. Radiology. 2010;255:53-61.

24. Nistri S, Sorbo MD, Marin M, Palisi M, Scognamiglio R, Thiene G. Aortic roo dilatation in young men with normally functioning bicuspid aortic valves. Heart 1999;82:19-22.

25. Girdauskas E, Disha K, Raisin HH, Secknus MA, Borger MA, Kuntze T. Risk of late aortic events after an isolated aortic valve replacement for bicuspid aortic valve stenosis with concomitant ascending aortic dilation. Eur J Cardiothorac Surg. 2012;42:832-7; discussion 837-8.

26. Sareyyupoglu B, Suri RM, Schaff HV, Dearani JA, Daly RC, Orszulak TA, et al Survival and reoperation risk following bicuspid aortic valve-sparing root replacement. J Heart Valve Dis. 2009;18:1-8.

27. Tamborini G, Galli CA, Maltagliati A, Andreini D, Pontone G, Quaglia C, et al. Comparison of feasibility and accuracy of transthoracic echocardiography versus computed tomography in patients with known ascending aortic aneurysm. Am J Cardiol. 2006;98:966-9.

28. Kari FA, Fazel SS, Mitchell RS, Fischbein MP, Miller DC. Bicuspid aortic valve configuration and aortopathy pattern might represent different pathophysiologic substrates. J Thorac Cardiovasc Surg. 2012;144:516-7.

29. Svensson LG, Al Kindi AH, Vivacqua A, Pettersson GB, Gillinov AM Mihaljevic T, et al. Long-term durability of bicuspid aortic valve repair. Ann Thorac Surg. 2014;97:1539-47; discussion 1548.

30. Kari FA, Liang DH, Kvitting JP, Stephens EH, Mitchell RS, Fischbein MP et al. Tirone David valve-sparing aortic root replacement and cusp repair for bicuspid aortic valve disease. J Thorac Cardiovasc Surg. 2013;145(3 Suppl): S35-40. e1-2.

31. Etz CD, Homann TM, Silovitz D, Spielvogel D, Bodian CA, Luehr M, et al Long-term survival after the Bentall procedure in 206 patients with bicuspid aortic valve. Ann Thorac Surg. 2007;84:1186-93; discussion 1193-4.

32. Park CB, Greason KL, Suri RM, Michelena HI, Schaff HV, Sundt TM III. Should the proximal arch be routinely replaced in patients with bicuspid aortic valve disease and ascending aortic aneurysm? J Thorac Cardiovasc Surg. 2011;142: $602-7$.

33. Roselli EE, Loor G, He J, Rafael AE, Rajeswaran J, Houghtaling PL, et al Distal aortic interventions after repair of ascending dissection: the argument for a more aggressive approach. J Thorac Cardiovasc Surg. 2015;149(2 Suppl):117-24.e3.

34. Safi HJ, Miller CC III, Estrera AL, Huynh TTT, Porat EE, Allen BS, et al. Staged repair of extensive aortic aneurysms: long-term experience with the elephant trunk technique. Ann Surg. 2004;240:677-85.

35. Svensson LG, Crawford ES, Hess KR, Coselli JS, Raskin S, Shenaq SA, et al. Deep hypothermia with circulatory arrest. Determinants of stroke and early mortality in 656 patients. J Thorac Cardiovasc Surg. 1993;106:19-28; discussion 2831.

36. Bulmer MG. Principles of Statistics. Mineola, NY: Dover; 1979.

Key Words: aneurysm, aorta, valves 


\section{APPENDIX E1. FACTORS (PATIENT \\ CHARACTERISTICS) CONSIDERED IN RANDOM \\ FOREST CLASSIFICATION \\ Demographics}

Sex, age $(\mathrm{y})$, height $(\mathrm{cm})$, weight $(\mathrm{kg})$

\section{Noncardiac Comorbidity}

Hypertension, smoking, diabetes, chronic obstructive pulmonary disease, myocardial infarction, history of carotid disease, stroke, ventricular arrhythmia

\section{Cardiac Disease}

Previous cardiac operation, number of previous cardiac operations, number of diseased coronary arteries $(>50 \%$ lesion), coronary artery dominance

\section{Symptoms}

New York Heart Association functional class

\section{Laboratory Data}

Creatinine $(\mathrm{mg} / \mathrm{dL})$, blood urea nitrogen $(\mathrm{mg} / \mathrm{dL})$, creatinine clearance, glomerular filtration rate (modification of diet in renal disease), total cholesterol $(\mathrm{mg} / \mathrm{dL})$, highdensity lipoprotein cholesterol (mg/dL), low-density lipoprotein cholesterol $(\mathrm{mg} / \mathrm{dL})$, triglycerides $(\mathrm{mg} / \mathrm{dL})$, bilirubin $(\mathrm{mg} / \mathrm{dL})$, hematocrit $(\%)$

\section{Valve Pathology}

Aortic valve stenosis, aortic valve regurgitation, aortic valve regurgitation grade, mitral valve regurgitation, mitral valve regurgitation grade, tricuspid valve regurgitation, tricuspid valve regurgitation grade, bicuspid valve fusion pattern, number of valve raphae, Sievers classification

\section{Echocardiographic Measurements}

Peak aortic valve gradient ( $\mathrm{mm} \mathrm{Hg}$ ), mean aortic valve gradient $(\mathrm{mm} \mathrm{Hg})$, left ventricular ejection fraction $(\%)$, fractional shortening, left ventricular inner diameter in diastole $(\mathrm{mm})$, left ventricular inner diameter in systole $(\mathrm{mm})$, left ventricular mass $(\mathrm{g})$, left ventricular mass index, left ventricular end-diastolic volume $\left(\mathrm{cm}^{3}\right)$, left ventricular end-systolic volume $\left(\mathrm{cm}^{3}\right)$, left ventricular end-diastolic volume index, left ventricular end-systolic volume index, left ventricular relative wall thickness $(\mathrm{mm})$, intraventricular septal thickness $(\mathrm{mm})$, posterior wall thickness $(\mathrm{mm})$, left atrial diameter $(\mathrm{mm})$, unscaled left atrial volume $\left(\mathrm{cm}^{3}\right)$, unscaled left atrial volume index

\section{Experience}

Interval from January 1, 2001, to date of operation 


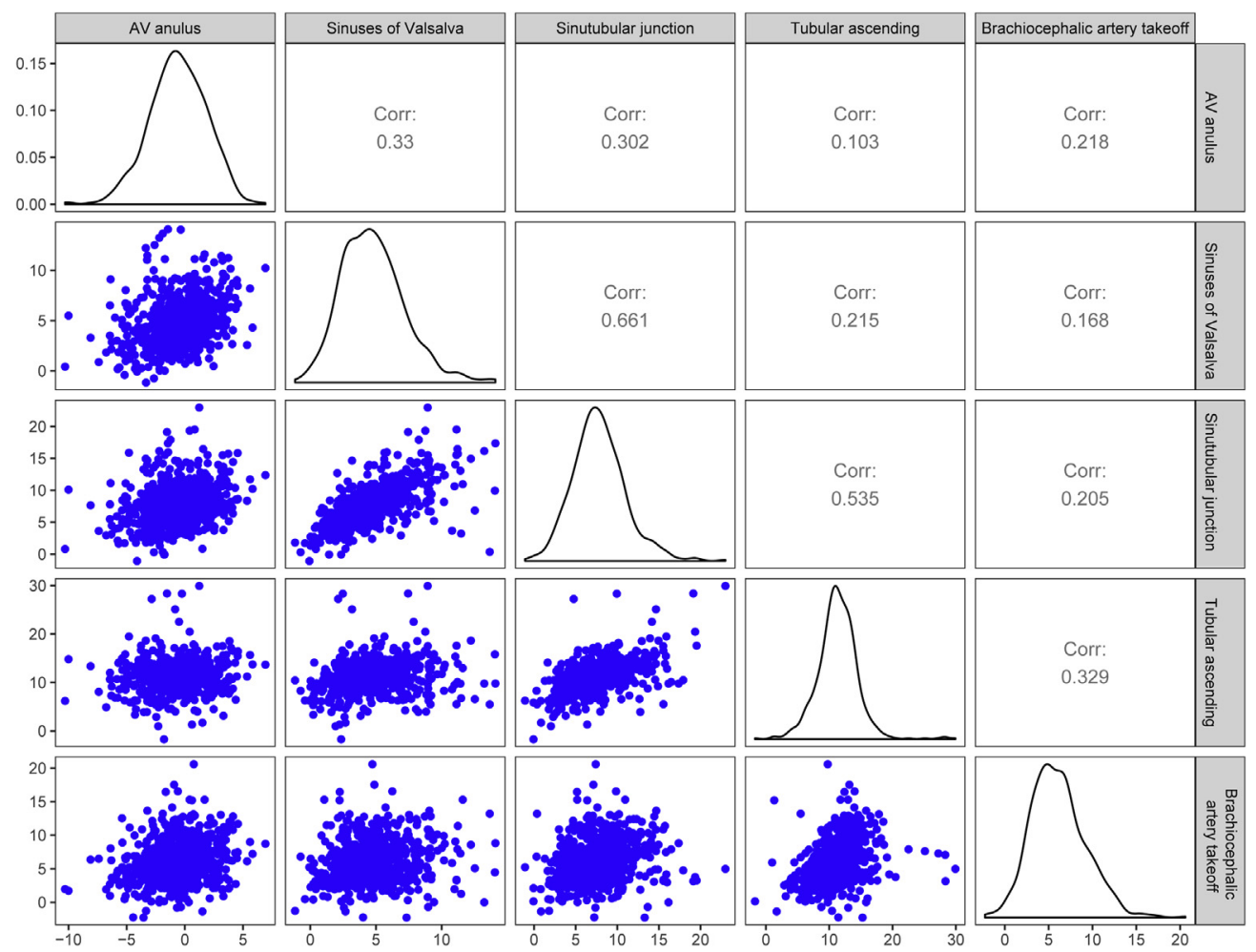

FIGURE E1. Distribution and scatter plots between pairs of landmark aortic diameter measurements expressed as $z$-values, and responding correlation (Corr) matrix. AV, Aortic valve. 


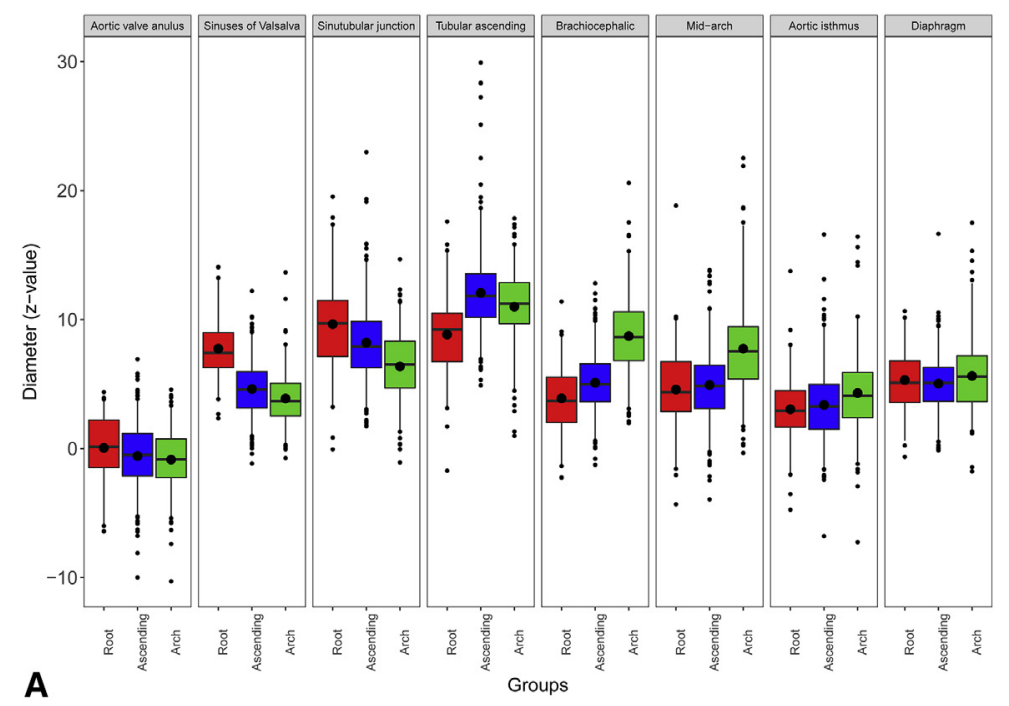

A

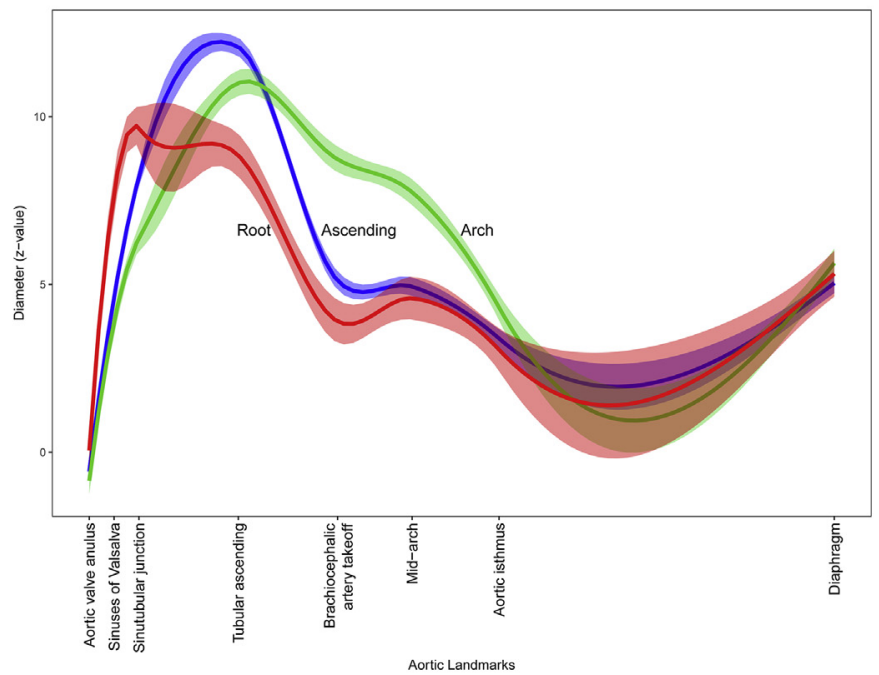

B

Aortic Landmarks

\section{C}

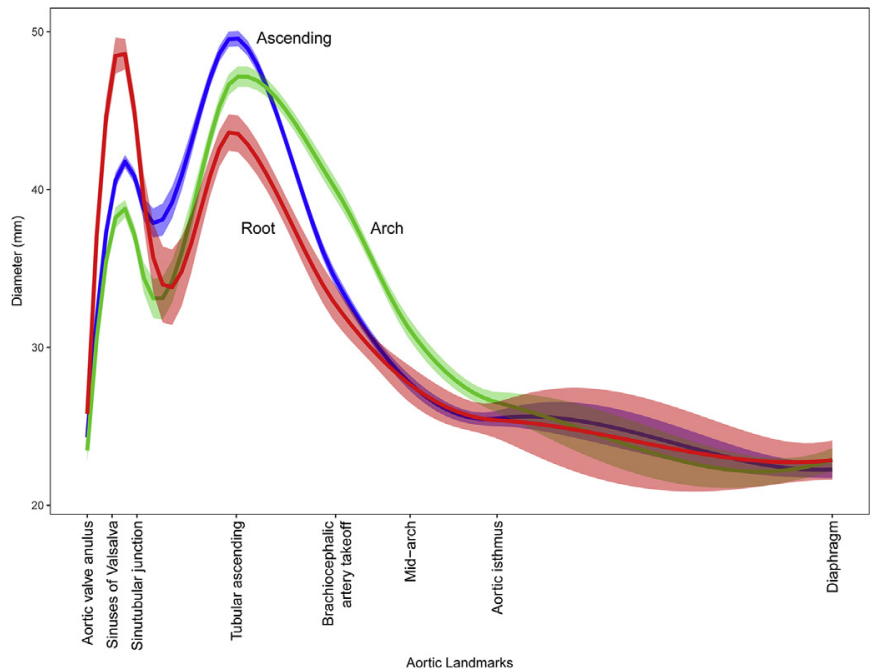

FIGURE E2. Aortic diameter $z$-values according to bicuspid aortic valve-associated aneurysm phenotypes: root (red), ascending (blue), and arch (green). A, Box-and-whiskers plot of data. Median z-value is represented by horizontal line in box and mean z-value by filled circles in box. Lower and upper borders of box represent 25th and 75th percentiles. Vertical whiskers represent 2.5 and 97.5 percentiles, and small filled circles represent measurements outside these whisker values. B, Smoothed representation with 2.5 and 97.5 percentiles shown as shaded colors. Distance between landmarks is average distance along centerline of flow between each landmark. Averages are displayed using a smoothing spline (R statistical software $\left.{ }^{20}\right)$. C, As in panel B, but using aortic diameter in millimeters. 


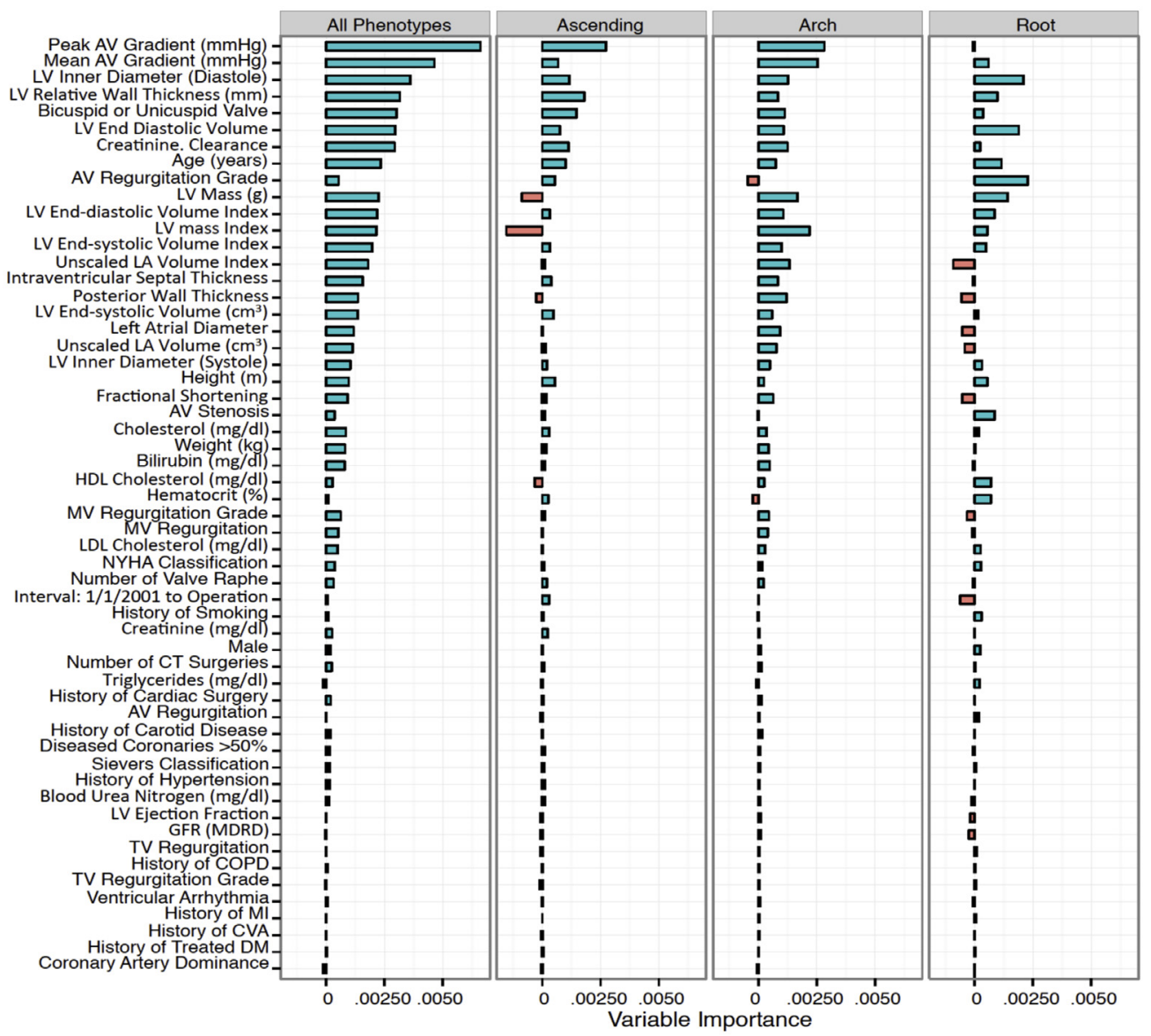

FIGURE E3. Random forest variable importance (VIMP) plots. VIMP is a measure of how the prediction error of the model changes when a variable is misspecified. Values $>0$ are associated with predictive accuracy. $A V$, Aortic valve; $L V$, left ventricular; $L A$, left atrial; $H D L$, high-density lipoprotein; $M V$, mitral valve; $L D L$, low-density lipoprotein; $N Y H A$, New York Heart Association; $C T$, cardiothoracic; $G F R$, glomerular filtration rate; $M D R D$, modification of diet in renal disease; $T V$, tricuspid valve; $C O P D$, chronic obstructive pulmonary disease; $M I$, myocardial infarction; $C V A$, cerebrovascular accident; $D M$, diabetes mellitus.

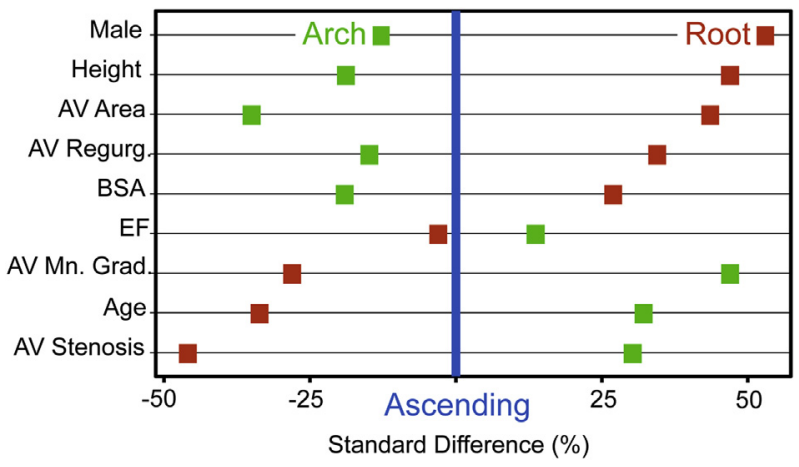

FIGURE E4. Patient characteristics by aortic phenotype. Presented are standardized differences of the root (red squares) and arch phenotypes (green circles) from the ascending phenotype (blue zero line) for key variables that showed significant differences between groups on univariate analysis. $A V$, Aortic valve; $B S A$, body surface area; $E F$, ejection fraction; Grad, gradient; Regurg, regurgitation. 